International Journal of Dental Research, 6(1) (2018) 35-40
International Journal of Dental Research
Website: $\begin{gathered}w w \text {. sciencepubco.com/index.php/IJDR } \\ \text { doi: } 10.14419 / \text { ijdr.v6il.9636 } \\ \text { Research paper }\end{gathered}$
RPC

\title{
Fracture tooth reattachment
}

\author{
Ahmed Mohammed Hassan ${ }^{1 *}$ \\ ${ }^{1}$ Assistant Professor, Department of Restorative Dental Science, Alfarabi Colleges for Dentistry and Nursing, Riyadh, KSA. \\ *Corresponding author E-mail: ahmed.altabbakh@alfarabi.edu.sa
}

\begin{abstract}
Anterior teeth fractures occur daily, with the main patient demand to restore esthetically the resultant defect. There is nothing more esthetic than the tooth itself. Many techniques were described to use the fractured piece to restore this defect in case of accurate fit. The objective of this article is to summarize these techniques to give the dental practitioners the opportunity to restore the fractured tooth more conservatively and in the same time more esthetically. In addition, it throws light on the prevalence and etiology of tooth fracture. Frontal teeth are subjected to traumas more than other teeth in the mouth. These traumas may lead to tooth fracture with or without pulp involvement. In attempts to restore the fractured tooth in more esthetic and conservative manner, the fractured piece may be used as a restorative material. This treatment modality has gained increased popularity among dental practitioner due to the continuous development in the adhesive field. Several techniques were used. These techniques include, simple reattachment, external chamfer, over contouring, internal dentin bevel, and internal enamel bevel. All these techniques try to afford the highest fracture resistance accompanied with the least possible tooth preparation. Combination of two or more technique would result in better performance.
\end{abstract}

Keywords: Bevel; Bonding; Reattachment; Tooth Fracture

\section{Introduction}

Anterior teeth compose the major role in esthetic smile appearance due to its position. Human teeth are very resilient but covered with enamel which is a brittle material (Yahyazadehfar et al. 2014). They are designed to withstand loads up to $700 \mathrm{n}$ for repeated millions of cycles during life (Anusavice 1996, p. 90-91, Okiyama et al. 2003). Surface crack on enamel is a common condition of the teeth but fortunately do not lead to tooth fracture (Yahyazadehfar et al. 2014). The minimum load required to propagate an incipient crack is $200 \mathrm{~N}$ (Barani et al. 2011).

Due to its position anterior teeth are subjected to numerous traumas. The covering enamel of the tooth resists tooth fracture to a great extent due to its complex microstructure and decussation of enamel rods. Decussation of enamel rods deflects cracks and prevents them from reaching the dentino-enamel junction (Yahyazadehfar et al. 2013, Yahyazadehfar et al. 2014). If the crack reaches the dentino-enamel junction it well serve as the second defense line against tooth fracture (Dong et al. 2003, Imbeni et al. 2003, Imbeni et a.1 2005, Park et al. 2008, Bechtle et a.1 2010). It is believed that tooth fracture occurs when the crack pass the dentinoenamel junction (Yahyazadehfar et al. 2014).

As enamel is the first defense line against tooth fracture, its thickness is very important factor in decreasing the possibility of fracture when the tooth is subjected to high loads (Lee et al. 2010). On the other hand, enamel tufts are considered as the weakest point in the enamel structure that may act as a starting point for the crack propagation (Chai et al. (Yahyazadehfar et al. 2014).

Etiology and prevalence:

The influence of the media on the patient demand to have a better smile is paramount. Attractiveness of the face is determined to a great extent by the appearance of anterior teeth (Tin-Oo et al. 2011). Teeth fracture is a common situation that dentist face in every day practice (Shetty et al. 2012, Pavone et al. 2016). Unfor- tunately, the most exposed part of the body to trauma is the maxilla and the most affected teeth are the maxillary incisors (Chaturvedi et al. 2013, Marwaha et al. 2015, Singaram et al. 2016). Trauma to the anterior teeth with subsequent fracture affects the social and psychological status of the patient negatively (Sargod \& Bhat 2010, Ninawe et al. 2013, Vishwanath et al. 2013). Tooth fracture due to maxillofacial trauma is about $26-48 \%$ (Gassner et al. 1999, Singaram et al. 2016).

Many causes may lead to maxillofacial trauma including fall on the face during sports or collision with other people or hard objects or even animals (Castro et al. 2005, Ferreira et al. 20015). One study conducted in India found that approximately $74 \%$ of maxillofacial trauma is due to traffic accidents, while falling on the face encountered for only $18 \%$ (Singaram et al. 2016). Another study performed in Brazil found that the largest percentage of tooth fracture is related to sport practice, while falling encountered for $14.6 \%$ with females more affected than male (Chaturvedi et al. 2013, Ferreira et al. 2015). Animals are responsible for about $14 \%$ of tooth injuries (Ferreira et al. 2015). This percentage may vary due to different environmental factors (Singaram et al. 2016).

Another study stated that falling is the main cause of dental trauma (Nagaveni \& Umashankara 2014). Falling of younger patient is related to their high activity in sports while for elderly patient lack of balance is the main cause for falling (Ferreira et al. 2015). In old age, dehydration of the tooth due to decreased salivary secretion also contributes to decrease the fracture resistance of the teeth (Baum 1981, Percival et al. 1994, Kruzic et al. 2003). Many studies have shown a reduced fracture toughness of elderly dentin (Koester et al. 2008, Yahyazadehfar et al. 2014). Nazari et al 2009 found a decreased resistance for crack propagation in old age dentin (Nazari et al. 2009). Other study also supports this finding (Kinney et al. 2005). The deal with old age patient becomes very important as there is an increase in the percentage of the elderly patient due to advancement in the medical care provided to them (Nazari et al. 2009). 
Tooth fracture also is a common situation in the dental injury among athletes who practice combat sports. Kickboxing is the most injurious] sport due to the higher force of kicks when compared to the punches (Shirani et al. 2010). Whatever the cause of the trauma, its intensity and extensiveness cannot be expected (Sargod\& Bhat 2010). Fortunately, dental trauma usually affects only one tooth (Ninawe et al. 2013).

Among patient seeking for treatment of non-carious lesion $31 \%$ was suffered from tooth fracture. It is the second reason to restore non carious lesion, while abrasion, abfraction, erosion (AAE) comes first (Nascimento et al. 11). The speech and mastication as well as esthetics are also greatly affected (Cortes et al. 2002, Lee $\&$ Divaris 2009). The most affected persons are those between 913 years old and individuals with over jet more than $5 \mathrm{~mm}$ (Chaturvedi et al. 2013).

\section{Diagnosis}

The fractured piece may be brought by the patient or in some cases embedded in the lip or the tongue (Hill \& Picton 1981, McDonnell \& McKiernan 1986, Agarwal et al. 2013, Barua et al. 2013Nagaveni et al. 2014, Marwaha et al. 2015). So if the patient came with a fracture tooth without the fractured piece with him, a through clinical and Radiographical examination should be conducted to exclude the possibility of being embedded in his lips or tongue. In most cases intraoral radiograph with the film placed between the fractured tooth and the lip is sufficient otherwise more complicated techniques as C.T. or even ultrasound may be performed (Barua et al. 2013).

\section{Treatment modalities}

When patient comes to the clinic with a fractured anterior tooth the real challenge of the dentist is to restore the esthetic in this critical region. Immediate treatment is advocated to restore the esthetic and to avoid further complications (Brullman et al. 2010, Nascimento et al. 2011). As the tooth fracture is a common situation, preparation of the dental practitioner to treat tooth fracture conservatively is paramount (Kulkarni et al. 2013).

Tooth fracture may be confined to enamel or enamel and dentin without pulp exposure; in this case it is classified as simple fracture. On the other hand, complicated fracture means involvement of the pulp in the fracture site (Giudice et al. 2017). The treatment of the fracture teeth depends - a great extent - on the type of fracture if it is simple or complicated. Treatment of simple fracture was done either by direct composite restoration or a full coverage crown, while in the complicated cases root canal treatment with post and core and may be followed by full coverage porcelain crown was the treatment of choice (Ninawe et al. 2013, Pavone et al. 2015). The disadvantages of the first technique are the instability of the composite shade and long term discoloration while the second technique is too aggressive scarifying the tooth vitality and possible wear of the opposing dentition (Pavone et al. 2015).

With the continuous development of bonding techniques and the achieved high bond strength, reattachment of the fractured piece to the fractured tooth has been emerged in the field of dental practice. This technique gains popularity every day. Some authors consider this treatment as the first choice (Yilmaz et al. 2008, Maitin et al. 2013, Giudice et al. 2017). While the first documented case for fracture tooth reattachment was carried out in 1964, the first author used acid etching technique was Tennery in 1978 (Tennery 1978, Shetty et al. 2012).

As aforementioned, tooth fracture may be simple (without pulp involvement) or complicated (with pulp involvement). In case of complicated tooth fracture, single visit endo followed by reattachment is usually required (Goenka et al. 2012, Kumari et al. 2012, Mahesh \& Jain 2016). Fiber post inserted in the pulp canal and connect the fractured piece with the remaining portion is a common technique (Goenka et al. 2012, Shetty et al. 2012, Maitin et al. 2013, Vishwanath et al. 2013, Sapna et al. 2014, Manju et al.
2015). The use of fiber post has many advantages. These advantages include, simple preparation technique, shorter preparation time, suitable young's modulus, and it reduces the stresses transmitted to the fractured piece (Akkayan 2004, Torabi \& Fattahi 2009, Akyuz \& Erdemir 2012, Krishna et al. 2012, Barua et al. 2013, Sapna et al. 2014). When the esthetic is of a prime concern, glass fiber post is the suitable solution for root canal treated tooth due to its translucency (Shetty et al. 2012, Manju et al. 2015). Although, most investigators suggest immediate reattachment of the fractured piece, delayed reattachment may be performed. Hiremath reported two months delay before reattachment procedure (Hiremath et al. 2012). In case of minor pulp exposure not exceeding $1 \mathrm{~mm}$, fracture reattachment also may be created in conjunction with direct pulp capping eliminating the need for further root canal treatment (Giudice et al. 2017, Mendes et al. 2017).

\section{Preliminary considerations}

Patient desire should be considered by the dental practitioner (Choudhary et al. 2015). Patient approval is a prerequisite for reattachment of the fractured piece otherwise another treatment modality may be performed (Nagaveni \& Umashankara 2014). Prior to reattachment procedure, the fractured piece should be well hydrated as dryness affects the tooth shade negatively. Dehydration of the fracture piece should be prevented by imbedding it in hank bank salt solution (Shetty et al. 2012). Hiremath et al used saline and thymol as anti-fungal agent (Hiremath et al. 2012). Storage of the fractured piece in milk till the time of the procedure is advocated by some authors (Mendes et al. 2017), while others used normal saline as storage media (Sargod \& Bhat 2010, Krishna et al. 2012, Sapna et al. 2014, Choudhary et al. 2015, Manju et al. 2015, Marwaha et al. 2015). Storage in water also has been reported (Chaturvedi et al. 2013, Kulkarni et al. 2013). In case of dehydration, some authors advocate placement of the fracture fragment in water for one hour to rehydrate it again and regain its normal translucency (Vijayaprabha et al. 2012).

Prior to reattachment procedures, disinfection of the fractured piece with $2 \%$ chlorohexidine or sodium hypochlorite has been described by some authors (Hiremath et al. 2012, Kumari et al. 2012, Manju et al. 2015, Giudice et al. 2017). Radiograph assessment is important to exclude any possibility of root fracture (Brullman et al. 2010, Choudhary et al. 2015, Giudice et al. 2017 . However the simplicity of reattachment procedure, a surgical flap may be required to expose the tooth margins if the fracture line located subgingivally (Pavone et al. 2016). Also, gingivectomy may be performed (Kulkarni et al. 2013). On the other hand some investigators stipulate supragigival fracture line to perform reattachment procedure (Giudice et al. 2017). In case of subgingival fracture some authors advocate orthodontic extrusion of the root to deal with the fracture supra-gingivally (Hiremath et al. 2012). Dental practitioner should keep in mind the importance of rubber dam application when dealing with adhesive techniques (Kulkarni et al. 2013). Light cure resin is usually used to reattach the fractured piece (Kumari et al. 2012, Kulkarni et al. 2013, Maitin et al. 2013, Davari \& Sadeghi 2014, Marwaha et al. 2015). Dual cured resin also was used to bond the fracture segment with the remainder of the tooth. It is a common procedure with the use of intraradicular post (Goenka et al. 2012, Krishna et al. 2012, Shetty et al 2012, Mendes et al. 2017). It is preferable to use total etch bonding system as it provide a stronger bond strength than self-etching systems (Davari \& Sadeghi 2014).

\section{Reattachment techniques}

Different techniques are used for reattachment procedure including, simple reattachment, external chamfer, over contouring, internal dentinal groove or external bevel (Shetty et al. 2012, Vijayaprabha et al. 2012, Kulkarni et al. 2013, Maitin et al. 2013, Abdulkhayum et al. 2014, Manju et al. 2015, Marwaha et al. 2015, 
Mendes et al. 2017). For simple reattachment technique, no further preparation is required for neither the fractured piece nor the remainder of the tooth (Sargod \& Bhat 2010, Shetty et al. 2012, Abdulkhayum et al. 2014). The bonding agent is applied on both the fractured piece and the remainder of the tooth followed by application of the composite resin without light curing of the bonding to ensure complete and accurate fit. The fracture line serves as a guide for accurate approximation. Then the light curing is conducted according to the manufacture instructions (Abdulkhayum et al. 2014). This technique is the most conservative one but it has the lowest fracture resistance (Reis et al. 2001, Abdulkhayum et al. 2014). On the other hand other researshers reported a 9 years clinical success of this technique (Sargod \& Bhat 2010). Another study also demonstrated a good performance of this technique after 4 years of follow up (Giudice et al. 2017). The use of this technique is limited by the accurate fit of the fracture piece without any discrepancies with the remainder of the tooth (Sargod \& Bhat 2010, Giudice et al. 2017). Vijayaprabha et al advocate the use of this technique if the fracture piece is very small (Vijayaprabha et al. 2012). In case of pulpal involvement, the use of fiber post decreases the need for further external preparation of bevels or internal preparation of grooves (Krishna et al. 2012).

The external chamfer technique requires preparation of $1 \mathrm{~mm}$ deep chamfer on the buccal surface of the fracture line after simple reattachment. This chamfer will be filled with a resin composite (Shetty et al. 2012, Abdulkhayum et al. 2014, Mahesh \& Jain 2016). It is less conservative than simple reattachment technique but it has a higher fracture resistance (Abdulkhayum et al. 2014) It also masks the fracture line making it less visible so enhancing the final esthetic (Kulkarni et al. 2013, Manju et al. 2015). Another technique similar to external chamfer technique is the external bevel technique. In this technique, the external bevel is performed to the fractured piece and the remainder of the tooth prior to reattachment. This encountered some degree of difficulty to reestablish accurate fit between the fractured piece and the remainder of the tooth (Vijayaprabha et al. 2012).

The over contour technique involves preparation of the buccal surface of both the fractured piece and the remainder of the tooth This preparation extends $2.5 \mathrm{~mm}$ from each side and its depth is $0.3 \mathrm{~mm}$. This step is done before the approximation of the two pieces together. The resulted space will be overfilled with a composite resin resulting in slightly over contoured buccal surface of the repaired tooth (Abdulkhayum et al. 2014). This technique is more destructive to the tooth structure than external chamfer technique but a marked increase in fracture resistance is observed (Abdulkhayum et al. 2014, Mendes et al. 2017). It is advocated to use this technique when there is a minor discrepancy between the fractured piece and the remainder of the tooth (Wiegand et al. 2005).

The internal dentinal groove technique gives a better fracture resistance than both simple reattachment technique and external chamfer technique. The fracture resistance of the repaired tooth with this technique is comparable to that of overcontoured technique. $1 \mathrm{~mm}$ depth and $1 \mathrm{~mm}$ width groove is prepared in both the fracture segment and the remainder of the tooth. The resulted space will be filled with composite resin prior to approximation (Reis et al. 2001, Hiremath et al. 2012, Kulkarni et al. 2013, Abdulkhayum et al. 2014, Mese et al. 2015, Mendes et al. 2017). In 1982 other researcher use an internal enamel grove to enhance the retention of the fractured piece (Walker 1996). The use of this technique has been decreased nowadays due to its difficulty and the little amount of available enamel (Vijayaprabha et al. 2012).

These techniques may be used solely or in combination to increase the fracture resistance of the repaired tooth (Bruke 1991, Kumari et al. 2012, Marwaha et al. 2015). One paper advocates the combination of over contouring with the internal grooves (Marwaha et al. 2015). Another authors used ribbond (polyethylene fiber) in conjunction with internal grooves to increase the overall strength of the repaired tooth (Hiremath et al. 2012). The choice among these techniques depends on many factors, such as the amount of the fracture, the ability to isolate the operating site, and the individual preference of the operator. Other factors include the periodontal status, involvement of the pulp, and the time elapsed (Choudhary et al. 2015).

Although most researchers believe that, the presence of the fractured piece is a prerequisite for the completion of the repair process (Sargod \& Bhat 2010, Tin-Oo et al. 2011, Goenka et al. 2012, Ninawe et al. 2013, Vishwanath et al. 2013, Marwaha et al. 2015, Mendes et al. 2017), there is an attempt to use a piece from another extracted tooth. Previously extracted tooth from another person was used. The selected tooth is similar some degree to the fractured tooth. Selective grinding was performed to shape and adapt a piece from the extracted tooth to the fracture site of the affected one. Then the reattachment procedure was carried out (Maitin et al 2013). However, this technique is more time consuming and has the risk of cross contamination as a tooth from another individual is used.

Reattachment procedure can be performed using the bonding system alone or in addition with restorative material to fill the minor discrepancies that may be found between the fracture segment and the remainder of the tooth (Davari \& Sadeghi 2014). Several restorative materials have been used to reattach the fracture segment These materials include, flowable composite, glass ionomer cement, resin modified glass ionomer, dual cure resin cement, and microhybrid composite. The worst was the resin modified glass ionomer (Shetty et al. 2012, Kulkarni et al. 2013, Marwaha et al. 2015, Goenka et al. 2012, Krishna et al. 2012, Singhal \& Pathak 2012, Maitin et al. 2013, Davari \& Sadeghi 2014, Mendes et al. 2017).

\section{Prognosis}

Follow up of the treated cases is very important to increase the lifetime of the repaired tooth. Various aspects should be verified in the follow up visits. These aspects include discoloration, mobility, periodontal status, and the vitality of the tooth (Vishwanath et al. 2013). Follow up of the reattached fracture piece has been done for various periods, starting from three months up to ten years (Sargod \& Bhat 2010, Goenka et al. 2012, Krishna et al. 2012, Kumari et al. 2012, Shetty et al. 2012, Vijayaprabha et al. 2012, Maitin et al. 2013, Ninawe et al. 2013, Sapna et al. 2014, Choudhary et al. 2015, Manju et al. 2015, Giudice et al. 2017, Mendes et al. 2017). We should keep in mind that a new trauma to the restored tooth is the main cause of failure (Reis et al. 2004). Another study found discoloration of the repaired tooth due to pulpal degeneration with periapical radiolucency after 10 years (Mendes et al. 2017). However the popularity acceptance of this technique, the fracture resistance of the restored teeth is still lower than that of sound ones (Davari \& Sadeghi 2014). On the other hand, another study reported a fracture resistance of the reassembled tooth as same as that of intact one (Choudhary et al. 2015). Badami et al. concluded that the fracture resistance is proportional to the surface area of the adhesion (Badami et al. 1995). Also, another study reported a long term performance of this technique better than that of direct composite restoration (Cavalleri \& Zerman 1995). If the fracture segment is about $50 \%$ of the crown a post treatment is recommended for better prognosis (Ninawe et al. 2013).

Many factors contribute to good prognosis of fracture reattachment procedure. Systematic approach to the coronal fracture has a positive impact on the prognosis of the treatment (Ninawe et al. 2013). Perfect adaptation and accurate fit is mandatory for the success of fracture reattachment procedure (Goenka et al. 2012). The material used to preserve the fractured piece till the time of reattachment plays an important role in the success of this treatment (Mendes et al. 2017). The lesser the dehydration period the better will be the prognosis (Shetty et al. 2012). Cooperation of the patient and his or her understanding of the advantages and disadvantages of this treatment modality play an important role for success of such treatment (Ninawe et al. 2013). 
Proper isolation of the working side with rubber dam is a mandatory requirement for the success of reattachment procedure which to proper bonding protocol and following the manufacturer's instructions play essential role in the high success rate of this treatment (Vishwanath et al. 2013). Mouth guard and patient education to know the limitation of this procedure will increase the life time of the repaired tooth (Andreasen et al. 1995, Kumari et al. 2012). Updating the knowledge of the dental practitioners about materials and techniques and the use of modern equipment would also increase the success rate (Krishna et al. 2012, Mahesh \& Jain 2016). utilizes the bonding strategies (Maitin et al. 2013, Vishwanath et al. 2013, Pavone et al. 2016, Giudice et al. 2017). Strict adherence Although many researchers consider the reattachment procedure as a permanent treatment for tooth fracture (Goenka et al. 2012, Abdulkhayum et al. 2014), there are many opponents the refuse this concept considering this treatment as a temporary treatment that requires prolonged follow up (Oieda-Gutierrez et al. 2011, Kumari et al. 2012, Mendes et al. 2017). All reattachment techniques are summarized in table (1).

Table 1: Summary of the Various Techniques Used for Fracture Piece Reattachment

\begin{tabular}{|c|c|c|c|c|}
\hline Technique & Procedures & Advantages & Disadvantages & Indication \\
\hline Simple reattament & $\begin{array}{l}\text { Simple approximation with no further } \\
\text { preparation }\end{array}$ & $\begin{array}{l}\text { The most conservative } \\
\text { technique }\end{array}$ & The least fracture resistance & $\begin{array}{l}\text { Small fracture piece with } \\
\text { perfect adaptation } \\
\text { Endodontically treated } \\
\text { tooth with fiber post }\end{array}$ \\
\hline External chamfer & $\begin{array}{l}1 \mathrm{~mm} \text { deep chamfer is performed on the } \\
\text { buccal surface at the fracture line after } \\
\text { reattachment and then filled with com- } \\
\text { posite }\end{array}$ & $\begin{array}{l}\text { Higher fracture resistance } \\
\text { than simple reattachment } \\
\text { Masking of the fracture } \\
\text { line }\end{array}$ & $\begin{array}{l}\text { Require scarifying with } \\
1 \mathrm{~mm} \text { of sound tooth struc- } \\
\text { ture }\end{array}$ & $\begin{array}{l}\text { Presence of the fractured } \\
\text { piece }\end{array}$ \\
\hline Over contour & $\begin{array}{l}\text { Reduction on the buccal surface extend } \\
2.5 \mathrm{~mm} \text { in both sides with } 0.3 \text { depth }\end{array}$ & $\begin{array}{l}\text { Higher fracture resistance } \\
\text { than external chamfer } \\
\text { technique }\end{array}$ & $\begin{array}{l}\text { The highest destructive } \\
\text { technique }\end{array}$ & $\begin{array}{l}\text { Presence of the fractured } \\
\text { piece } \\
\text { Minor } \\
\text { discrepancy between the } \\
\text { fractured piece and the } \\
\text { remainder of the tooth }\end{array}$ \\
\hline Internal grove & $\begin{array}{l}1 \mathrm{~mm} \text { depth grove in prepared in both } \\
\text { the fractured piece and the remainder of } \\
\text { the tooth to be filled with composite } \\
\text { prior to reattachment }\end{array}$ & $\begin{array}{l}\text { High fracture resistance } \\
\text { as over contour technique }\end{array}$ & $\begin{array}{l}\text { Very difficult due to the } \\
\text { limited available structure in } \\
\text { the fractured piece }\end{array}$ & $\begin{array}{l}\text { Presence of large fractured } \\
\text { piece }\end{array}$ \\
\hline $\begin{array}{l}\text { Allogeneic tooth } \\
\text { fragment reat- } \\
\text { tachment }\end{array}$ & $\begin{array}{l}\text { A piece from another extracted tooth is } \\
\text { milled to mimic the missing part of the } \\
\text { fractured tooth }\end{array}$ & $\begin{array}{l}\text { Use of natural substitute } \\
\text { with the same mechanical } \\
\text { and physical properties }\end{array}$ & $\begin{array}{l}\text { Time consuming } \\
\text { Risk of contamination }\end{array}$ & $\begin{array}{l}\text { Absence of the fractured } \\
\text { piece }\end{array}$ \\
\hline
\end{tabular}

\section{Discussion}

The shade of the teeth is a major factor affecting the patient acceptance to his appearance (Tin-Oo et al. 2011). Determining the restoration shade to be identical to that of the affected tooth in every situation is too difficult due to difference in the optical properties (Joiner 2004, Tin-Oo et al. 2011). Natural esthetics, time saving, absence of laboratory steps, and patient satisfaction are the advantages of tooth fragment reattachment (Goenka et al. 2012, Abdulkhayum et al. 2014). The use of the fracture piece itself as a restorative material will result in color stability (Shetty et al. 2012), the same surface texture as the remainder of the tooth (Chazine et al. 2011, Oieda-Gutierrez et al. 2011, Ninawe et al 2013, Vas et al. 2014), and the same translucency (Krishna et al 2012, Vijayaprabha et al. 2012). One disadvantage of resin composite is the possibility of wear due to harder opposing enamel. This disadvantage is eliminated by reattachment of the fractured piece. Also, fragment reattachment protects the opposing dentition from wear due to harder porcelain crown (Baratieri et al. 1994, Goenka et al. 2012, Kumari et al. 2012, Vijayaprabha et al. 2012, Abdulkhayum et al. 2014). It also has a positive emotion influence on the patient as he maintained his natural tooth back (Kumari et al. 2012, Manju et al. 2015). As the strength of the tooth is proportional to the amount of tissue removal, this technique is the least destructive to the remaining tooth structure enhancing the strength of the restored tooth (Pavone et al. 2016). Fracture piece reattachment is a simple technique saving the time of patient and dentist as well as it is the most conservative treatment (Shetty et al. 2012, Giudice et al. 2017).

Although the numerous advantages of fracture reattachment approach, there is no technique without disadvantages. The fracture resistance of the tooth is decreased by about $50-60 \%$ after reat- tachment procedures (Shetty et al. 2012). Also, a continuous and prolonged follow up is necessary (Sargod \& Bhat 2010, Goenka et al. 2012, Krishna et al. 2012, Kumari et al. 2012, Vijayaprabha et al. 2012, Maitin et al. 2013, Ninawe et al. 2013, Sapna et al. 2014, Choudhary et al. 2015, Manju et al. 2015, Giudice et al. 2017, Mendes et al. 2017). Degradation of the bonding at the interface may lead to re-fracture, also color change of the fracture segment may occur if it is allowed to be dehydrated (Vijayaprabha et al. 2012, Abdulkhayum et al. 2014, Mahesh \& Jain 2016). One study demonstrated hyper sensitivity of the treated teeth after 3 years follow up (Giudice et al. 2017). If the repaired tooth was restored with a post, its brightness and translucency will be decreased (Vijayaprabha et al. 2012). Although the simplicity of fracture reattachment procedure, this technique becomes complex when there are multiple fracture of the same tooth. In this case restoration with composite resin will be a good alternative (Hall 1998).

\section{Conclusions}

Reattachment of the fractured piece of frontal tooth is simple and successful treatment. This procedure can be performed by different techniques. Combination of two or more technique would result in better performance.

Disclosure Statement: The author declares there is no conflict of interest.

\section{References}

[1] Yahyazadehfar M, Ivancik J, Majd H, An B, Zhang D, Arola D. On the mechanics of fatigue and fracture in teeth. Appl Mech Rev. 2014; 66:0308031-03080319. https://doi.org/10.1115/1.4027431. 
[2] Anusavice, K. J. Phillip's Science of Dental Materials, 11th ed., Saunders, Philadelphia, 1996; 90-91.

[3] Okiyama, S., Ikebe, K., Nokubi, T. Association between masticatory performance and maximal occlusal force in young men. J Oral Rehab. 2003; 30:278-282. https://doi.org/10.1046/j.13652842.2003.01009.x.

[4] Barani A, Keown AJ, Bush MB, Lee JJ, Chai H, Lawn BR. Mechanics of longitudinal cracks in tooth enamel. Acta Biomater. 2011; 7:2285-92. https://doi.org/10.1016/j.actbio.2011.01.038.

[5] Yahyazadehfar M, Bajaj D, Arola DD. Hidden contribution of the enamel rod on the fracture resistance of the human teeth. Acta Biomater. 2013

9:4806-14 https://doi.org/10.1016/j.actbio.2012.09.020.

[6] Dong XD, Ruse ND. Fatigue crack propagation path across the dentinoenamel junction complex in human teeth. J Biomed Mater Res A. 2003; 66:103-9. https://doi.org/10.1002/jbm.a.10541.

[7] Imbeni V, Nalla, RK, Bosi C, Kinney JH, Ritchie RO. In vitro fracture toughness of human dentin. J Biomed Mater Res A. 2003; 66:1-9. https://doi.org/10.1002/jbm.a.10548.

[8] Imbeni V, Kruzic JJ, Marshall GW, Marshall SJ, Ritchie RO. The dentin-enamel junction and the fracture of human teeth. Nat Mater. 2005; 4:229-32. https://doi.org/10.1038/nmat1323.

[9] Park S, Quinn JB, Romberg E, Arola D. On the brittleness of enamel and selected dental materials. Dent Mater. 2008; 24:1477-85. https://doi.org/10.1016/j.dental.2008.03.007.

[10] Bechtle S, Fett T, Rizzi G, Habelitz S, Klocke A, Schneider GA Crack arrest within teeth at the dentinoenamel junction caused by elastic modulus mismatch. Biomaterials. 2010; 31:4238-47. https://doi.org/10.1016/j.biomaterials.2010.01.127.

[11] Lee JJ, Morris D, Constantino PJ, Lucas PW Smith TM, Lawn BR Properties of tooth enamel in great apes. Acta Biomater. 2010; 6: 4560-5. https://doi.org/10.1016/j.actbio.2010.07.023.

[12] Chai H, Lee JJ, Lawn BR. Fracture of tooth enamel from incipient microstructural defects. J Mech Behav Biomed Mater. 2010; 3:11620. https://doi.org/10.1016/j.jmbbm.2009.08.002.

[13] Tin-Oo MM, Saddki N, Hassan N. Factors influencing patient satisfaction with dental appearance and treatments they desire to improve aesthetics. BMC Oral Health. 2011 11:6. https://doi.org/10.1186/1472-6831-11-6.

[14] Shetty PP, Metgud S, Jain A, Dhillon G, Astekar M. A conservative single visit reattachment of fractured crown fragment. Clinics and Practice. 2012; 2(3):e70. https://doi.org/10.4081/cp.2012.e70.

[15] Pavone AF, Ghassemian M, Mancini M, Condo R, Arcuri C, Pasquantonio Get. Autogenous tooth fragment adhesive reattachment for a complicated crown root fracture: Two interdisciplinary case reports. Case Rep Dent. 2016; 2016:9352129. https://doi.org/10.1155/2016/9352129.

[16] Chaturvedi R, Kumar A, Rana V, Aggarwal A, Chandra L. A correlation of permanent anterior tooth fracture with type of occlusion and craniofacial morphology. Int J Clin Pediatr Dent. 2013; 6:8084. https://doi.org/10.5005/jp-journals-10005-1194.

[17] Marwaha M, Bansal K, Srivastava A, Maheshwari N. Surgical retrieval of tooth fragment from lower lip and reattachment after 6 months of trauma. Int J Clin Pediatr Dent. 2015; 8:145-8. https://doi.org/10.5005/jp-journals-10005-1302.

[18] Singaram M, G SV, Udhayakumar RK. Prevalence, pattern, etiology, and management of maxillofacial trauma in a developing country: A retrospective study. J Korean Assoc Oral Maxillofac Surg. 2016; 42: 174-81. https://doi.org/10.5125/jkaoms.2016.42.4.174.

[19] Sargod SS, Bhat SS. A 9-year follow-up of a fractured tooth fragment reattachment. Contemp Clin Dent. 2010; 1:243-5.

[20] Ninawe N, Doifode D, Khandelwal V, Nayak PA. Fragment reattachment of fractured anterior teeth in a young patient with a 1.5 year follow-up. BMJ Case Reports. 2013; 2013:bcr2013009399. https://doi.org/10.1136/bcr-2013-009399.

[21] Vishwanath B, Faizudin U, Jayadev M, Shravani S. Reattachment of coronal tooth fragment: Regaining back to normal. Case Reports in Dentistry. 2013; 2013:286186. https://doi.org/10.1155/2013/286186.

[22] Gassner R, Bösch R, Tuli T, Emshoff R. Prevalence of dental trauma in 6000 patients with facial injuries: Implications for prevention. Oral Surg Oral Med Oral Pathol Oral Radiol Endod 1999; 87: 27-33.

[23] Castro JC, Poi WR, Manfrin TM, Zina LG. Analysis of the crownroot fracture due to dental trauma assisted by the Integrated Clinic from 1992 to 2002. Dent Traumatol. 2005; 21: 121-6. https://doi.org/10.1111/j.1600-9657.2005.00276.x.

[24] Ferreira MC, Batista AM, Marques LS, Ferreira F de O, MedeirosFilho JB, Ramos-Jorge ML. Retrospective evaluation of tooth inju- ries and associated factors at a hospital emergency ward. BMC Oral Health. 2015; 15:137. https://doi.org/10.1186/s12903-015-0125-4.

[25] Nagaveni NB, Umashankara KV. Tooth fragment embedded in the lower lip for 10 months following dentoalveolar trauma: A case report with literature review. Burns \& Trauma. 2014; 2:141-five. https://doi.org/10.4103/2321-3868.1356520.

[26] Baum BJ. Evaluation of stimulated parotid saliva flow rate in different age groups. J Dent Res. 1981; 60: 1292-6 https://doi.org/10.1177/00220345810600070101.

[27] Percival RS, Challacombe SJ, Marsh PD. Flow rate of resting whole and stimulated parotid saliva in relation to age and gender. $\mathrm{J}$ Dent Res. 1994; 73: 1416-20. https://doi.org/10.1177/00220345940730080401.

[28] Kruzic JJ, Nalla RK, Kinney JH, Ritchie RO. Crack blunting, crack bridging and resistance curve fracture mechanics in dentin: Effect of hydration. Biomaterials. 2003; 24:5209-21.

[29] Koester KJ, Ager JW 3rd, Richie RO. The effect of aging on crackgrowth resistance and toughening mechanisms in human dentin 2008 ; 29: 1318-28. https://doi.org/10.1016/i.biomaterials.2007.12.008.

[30] Nazari A, Bajaj D, Zhang D, Romverg E, Arola D. Aging and the reduction in fracture toughness of human dentin. J Mech Bahav Biomed Mater. 2009; 2: 550-9. https://doi.org/10.1016/j.jmbbm.2009.01.008.

[31] Kinney JH, Nalla RK, Pople JA, Ritchie RO. Age-related transparent root dentin: Mineral concentration, crystallite size, and mechanical properties. Biomaterials. 2005; 16 3363-76. https://doi.org/10.1016/j.biomaterials.2004.09.004.

[32] Shirani G, Kalantar Motamedi MH, Ashuri A, Eshkevari PS. Prevalence and patterns of combat sport related maxillofacial injuries. J Emerg Trauma Shock. 2010; 3:314-17. https://doi.org/10.4103/0974-2700.70744.

[33] Nascimento MM, Gordan VV, Qvist V, Bader JD, Rindal DB, Williams OD, Gewartowski D, Fellows JL, Litaker MS, Gilbert GH Restoration of non-carious tooth defects by dentists in the dental practice-based research network - DPBRN. J Am Den Assoc. 2011 142:1368-75. https://doi.org/10.14219/jada.archive.2011.0138.

[34] Cortes MI, marcenes W, Sheiham A. Impact of traumatic injuries to the permanent teeth on the oral health-related quality of life in 12 14 year-old children. Community Dent Oral Epidemiol. 2002; 30: 193-8. https://doi.org/10.1034/j.1600-0528.2002.300305.x.

[35] Lee JY, Divaris K. Hidden consequence of dental trauma: the social and psychological effects. Pediatr dent. 2009; 31: 96-101.

[36] Hill FJ, Picton JF. Fractured incisor fragment in the tongue: A case report. Pediatr Dent 1981; 3:337-8.

[37] McDonnell DG, McKiernan EX. Broken tooth fragments embedded in the tongue: A case report. Br J Oral Maxillofac Surg 1986; 24:464-6.

[38] Agarwal A, Rehani U, and Rana V, Gambhir N. Tooth fragment embedded in the upper lip after dental trauma: A case report presenting an immediate diagnostic approach and complete rehabilitation. J Indian Soc Pedod Prev Dent. 2013; 31:52-5 https://doi.org/10.4103/0970-4388.112415.

[39] Barua P, Chaudhary S, Kaur H, Mallikarjuna R. Treatment imprudence leading to missed tooth fragment. BMJ Case Reports. 2013; 2013:bcr2013009154. https://doi.org/10.1136/bcr-2013-009154.

[40] Brullman D, Schulze RK, d'Hoedt B. The treatment of anterior dental trauma. Dtsch Arzteb Int. 2010; 108: 565-70.

[41] Kulkarni VK, Sharma DS, Banda NR, Solanki M, Khandelwal V, Airen P. Clinical management of a complicated crown-root fracture using autogenous tooth fragment: A biological restorative approach. Contemp Clin Dent. 2013; 4:84-7. https://doi.org/10.4103/0976237X.111603.

[42] Giudice G L, Alibrandi A, Lipari F, Lizio A, Lauritano F, Cervino C, Cicciu M. The coronal tooth fractures: Preliminary evaluation of a three-year follow-up of the anterior teeth direct fragment reattachment technique without additional preparation. Open Dent J. 2017; 11:266-275. https://doi.org/10.2174/1874210601711010266.

[43] Yilmaz Y, Zehir C, Eyuboglu O, Belduz N. Evaluation of success in the reattachment of coronal fractures. Dental Traumatol 2008; 24:151-8. https://doi.org/10.1111/j.1600-9657.2007.00532.x.

[44] Maitin N, Maitin SN, Rastogi K, Bhushan R. Fracture tooth fragment reattachment. BMJ Case Reports. 2013; 2013:bcr2013009183. https://doi.org/10.1136/bcr-2013-009183.

[45] Tennery NT. The fractured tooth reunited using the acid-etch bonding technique. Tex Dent J. 1978; 96:16-7.

[46] Goenka P, Sarawgi A, Dutta S. A conservative approach toward restoration of fractured anterior tooth. Contemp Clin Dent. 2012; 3:S67-70. https://doi.org/10.4103/0976-237X.95109. 
[47] Kumari NBPS, Sujana V, Sunil CHR, Reddy PS. Reattachment of complicated tooth fracture: An alternative approach. Contemp Clin Dent. 2012; 3:242-4. https://doi.org/10.4103/0976-237X.96843.

[48] Mahesh Patni P, Jain Patni M. A conservative approach to the management of a dental trauma for immediate natural esthetics. Arch Trauma res. 2016; 4: e29042. https://doi.org/10.5812/atr.29042.

[49] Maitin N, Maitin S, Rastogi K, Bhushan R. Allogenous tooth fragment reattachment. BMJ Case Rep. 2013; 2013:bcr2013010298. https://doi.org/10.1136/bcr-2013-010298.

[50] Sapna CM, Priya R, Sreedevi NB, Rajan RR, Kumar R. Reattachment of Fractured Tooth Fragment with Fiber Post: A case series with 1-year followup. Case Rep Dent. 2014; 2014:376267. https://doi.org/10.1155/2014/376267.

[51] Manju M, Shanthrai SL, SAvitha KC, Sethi N. Esthetic and biologic mode of reattaching incisor fracture fragment utilizing glass fibe post. J Nat Sci Biol Med. 2015; 6: 446-8. https://doi.org/10.4103/0976-9668.160033.

[52] Akkayan B. An in vitro study evaluating the effect of ferrule length on fracture resistance of endodontically treated teeth restored with fiber-reinforced and zirconia dowel systems. J Prosthet Dent. 2004; 92: 155-62. https://doi.org/10.1016/j.prosdent.2004.04.027.

[53] Torabi K, Fattahi F. Fracture resistance of endodontically treated teeth restored by different FRC posts: An in vitro study. Indian J Dent Res. 2009; 20: 282-7. https://doi.org/10.4103/09709290.57359

[54] Akyuz SN, Erdemir A. Restoration of tooth fractures using fiber post and fragment reattachment: Three case reports. Eur J Gen Dent. 2012; 1:94-8 https://doi.org/10.4103/2278-9626.103393.

[55] Krishna A, Malur MH, Swapna DV, Benjamin S, Deepak CA Traumatic dental injury - an enigma for adolescents: A series of case reports. Case Rep Dent. 2012; 2012:756526. https://doi.org/10.1155/2012/756526.

[56] Hiremath H, Kulkarni S, Saikalyan S, Chordhiya R. Use of ribbond and panavia $\mathrm{F}$ cement in reattaching fractured tooth fragments of vital maxillary anterior teeth. Contemp Clin Dent. 2012; 3:478-80. https://doi.org/10.4103/0976-237X.107446.

[57] Mendes L, Laxe L, Passos L. Ten-year follow up of a fragment reattachment to anterior teeth: A conservative approach. Case Rep Dent. 2017:2017: 2106245. https://doi.org/10.1155/2017/2106245.

[58] Choudhary A, Garg R, Bhalla A, Khatir RK. Tooth fragment reattachment: an esthetic, biological restoration. J Nat Sci Biol Med. 2015; 6: 205-7. https://doi.org/10.4103/0976-9668.149123.

[59] Vijayaprabha K, Marwah N, Dutta S. A biological approach to crown fracture: Fracture reattachment: A report of two cases. Contemp Clin Dent. 2012; 3:S194-8 https://doi.org/10.4103/0976-237X.101091.

[60] Davari A, Sadeghi M. Influence of Different Bonding Agents and Composite Resins on Fracture Resistance of Reattached Incisal Tooth Fragment. J Dent (Shiraz). 2014; 15:6-14.

[61] Abdulkhayum A, Munjal S, Babaji P, Chaurasia VR, Munjal S, Lau H, Olekar ST, Lau M. In-vitro evaluation of fracture strength recovery of reattached anterior fractured tooth fragment using different re-attachment techniques. Journal of clinical and diagnostic research: $\quad$ JCDR. 2014; 8:208-11. https://doi.org/10.7860/JCDR/2014/7161.4164.

[62] Reis A, Francci C, Loguercio AD, Carrilho MRO, Filho LER. Reattachment of anterior fractured teeth: Fracture strength using different technique. Oper Dent. 2001; 26: 287-94

[63] Wiegand A, Rödig T, Attin T. Treatment of crown-fractured incisors: Reattachment instead of restoration. Schweiz Monatsschr Zahnmed. 2005; 115: 1172-81.

[64] Mese M, Akcay M, Yasa B, Akcay H. Multidisciplinary Management of Complicated Crown-Root Fracture of an Anterior Tooth Undergoing Apexification. Case Rep Dent. 2015; 2015:521013. https://doi.org/10.1155/2015/521013.

[65] Walker M. Fractured tooth fragment reattachment. Gen Dent 1996; 44; 434-6.

[66] Bruke FJ. Reattachment of a fractured central incisor tooth fragment. Br Dent J. 1991; 170:223-5 https://doi.org/10.1038/sj.bdj.4807484.

[67] Singhal R, Pathak A. Comparison of the fracture resistance of reattached incisor tooth fragment using 4 different materials. J Indian Soc Pedod Prev Dent. 2012; 30: 310-6. https://doi.org/10.4103/0970-4388.108927.

[68] Reis A, Loguercio AD, Kraul A, Matson E. Reattachment of fractured teeth: A review of literature regarding techniques and materials. Oper Dent 2004; 29:226-33.

[69] Badami AA, Dunne SM, Scheer B An in vitro investigation into the shear bond strengths of two dentine-bonding agents used in the reattachment of incisal edge fragments. Endod Dent Traumatol.
$1995 ; 11: 129-35$

https://doi.org/10.1111/j.1600 9657.1995.tb00474.x.

[70] Cavalleri G, Zerman N. Traumatic crown fractures in permanen incisors with immature roots: A follow-up study. Endod Dent Traumatol 1995; 11:294-6. https://doi.org/10.1111/j.16009657.1995.tb00507.x.

[71] Andreasen FM, Norén JG, Andreasen JO, Engelhardtsen S, LindhStrömberg U. Long term survival of fragment bonding in the treatment of fractured crowns. Quintessence Int. 1995;26:669-81

[72] Oieda-Gutierrez F, Martinez-Marquez B, Rosales-Guillen AJ. Reattachment of anterior teeth fragments using a modified Simonsen's technique after dental trauma: Report of a case. Dent Traumatol. 2011; 27: 81-5. https://doi.org/10.1111/j.1600-9657.2010.00964.x.

[73] Joiner A. Tooth colour: A review of the literature. J Dent. 2004; 32: 3-12. https://doi.org/10.1016/j.jdent.2003.10.013.

[74] Vaz VTP, Presoto CD, Jordao KCF, Paleari AG, Dantas A.A.-R, Segalla JCM, de Oliveira Junior OB. Fragment reattachment after atypical crown fracture in maxillary central incisor. Case Rep Dent. 2014; 2014:231603. https://doi.org/10.1155/2014/231603.

[75] Chazine M, Sedda M, Ounsi HF, Paragliola R, Ferrari M, Grandini $\mathrm{S}$. Evaluation of the fracture resistance of reattached incisal fragments using different materials and techniques. Dent Traumatol. 2011; 1: 15-8. https://doi.org/10.1111/j.1600-9657.2010.00951.x.

[76] Baratieri LN, Monteiro S, Júnior, de Albuquerque FM, Vieira LC, de Andrada MA, de Melo Filho JC. Reattachment of a tooth fragment with a 'new' adhesive system: A case report. Quintessence Int. 1994;25:91-6

[77] Hall DA. Restoration of a shattered tooth. J Am Dent Assoc. 1998 ; 129:105-6. https://doi.org/10.14219/jada.archive.1998.0031. 